PERIODICALS OF ENGINEERING AND NATURAL SCIENCES

Vol. 5 No. 1 (2017) - Special Issue (Recent Topics in Environmental Science)

Available online at: http://pen.ius.edu.ba

\title{
The Production of Polyurethane from Waste Vegetable Oil-Based Polyols and Modelling of Rheological Properties
}

\author{
Ercan Aydoğmuş \\ Department of Chemical Engineering, Faculty of Engineering, \\ Firat University, 23119, Elazı̆g, Turkey
}

\author{
Fethi Kamışlı \\ Department of Chemical Engineering, Faculty of Engineering, \\ Firat University, 23119, Elazı̆ $\breve{g}$ Turkey
}

\begin{abstract}
Polyols in polyurethane production is of great importance. The future will increase the production of polyols from renewable sources. The result of the reduction of fossil fuels will be important in the use of renewable resources. Especially important alternative which will expand polyols production from vegetable oils. Polyols derived from vegetable oil will be produced by epoxidation, hydroxylation and purification.

In this study, some vegetable-oil based polyols were produced from the different wastes vegetables oils with the catalysts. The produced polyols compared with commercial polyols with rheological properties as viscosity, temperature, shear stress, shear rate. The rheological properties of the polyols were modelling with general equations based on experimental data.

Polyurethane produced from waste vegetable oil-based polyols and investigated density and effective thermal conductivity.
\end{abstract}

Keywords: Waste Vegetable Oil-Based Polyols; Polyurethane; Rheological Properties; Modelling

\section{Introduction}

Polyurethane, low thermal conductivity, easy to use, flexibility, high mechanical strength, it is preferred in many fields. Polyols are the most important raw materials in the polyurethane industry. But the world's oil supply is decreasing rapidly with each passing day. Therefore, an inquiry from renewable sources that can replace the petroleum-based polyol. The common view is that the natural plant and animal oils of alternative raw materials.

Studies in the literature have epoxidized oil-based polyether polyol instead of soy-based polyols were produced using the vegetable oil.

Compared to petroleum-based polyols in polyurethane production from vegetable oil polyol produced with a smaller amount of isocyanate used. The polyurethane produced with the polyol produced from vegetable oil decreased compression resistance [8].

The polyurethane material in the work they added crystallized calcium carbonate and silica particles. It has been shown to become smaller the size of filler by adding the closed spherical cells. Mechanical properties of polyurethane materials were modeled. Moreover, the effect of the particle size of the filler was investigated [11].
Wood powder was added as filler to the polyurethane derived from castor oil-based polyol. The polyurethane of the swelling time was compared with commercial polyols, and castor oil-based polyols. Increasing the filler had negative impact on the effective thermal conductivity. Effective thermal conductivity compared to commercial polyurethane material of the castor oilbased polyurethane material has been found to be lower. Increasing the filler has negative impact on the effective heat transfer coefficient. Density polyurethane material has been found to be between 36 and $39 \mathrm{~kg} / \mathrm{m}^{3}$. TGA value of the thermal stability of the castor oilbased polyurethane material has been found to be more commercially polyol product [12].

Boron organic compounds were used as filler in polyurethane production. Boron organic based polyurethane compounds were observed that decrease with the increase friability. Boron organic compounds rates were seen to increase with the increase of compressive strength. The softening temperature has been found that increasing the content of boron organic compounds fell from $230^{\circ} \mathrm{C}$ to $180^{\circ} \mathrm{C}$ [16].

The goal of this study is to determine the rheological properties and modeling for polyols and the viscosity to each waste vegetable oil based-polyols are measured at different temperatures $\left(25,30,35,40,45\right.$ and $\left.50{ }^{\circ} \mathrm{C}\right)$ by using a rotary viscometer (Brookfield DV-II). Samples were sheared with several different rotational speeds at 
an increasing order. One of the most important parameters required in the design of technological processes in polyurethane industries the viscosity of raw materials. Data obtained for apparent viscosity and rotational speed were used to describe the flow behavior by the model equations both in the forward (increasing shear rate) and backward (decreasing shear rate) - measurement.

\section{Material and Methods}

The polyols are produced from the waste vegetable oils in three consecutive steps which are epoxidation, hydroxylation and purification. The temperature of the system is kept under the control in order to keep temperature at certain value. When it is reached to the desired reaction temperature, the peroxides are added into the vegetable oils in acidic medium by the aid of dropping funnel in the certain time.

After the reaction is completed, the mixture is taken into separatory funnel and after for a while the mixture separates in two phases with the upper phase of the epoxidized vegetable oil. After the epoxidation step, neutralization with water and the hydroxylation starts. Especially hydroxylation with alcoholysis is frequently preferred in the production of polyols. The purification process is being carried with rotary evaporator to get rid of impurities such as water, heptane and etc. The polyols produced from the vegetable oil are being used in the production of polyurethane by checking the number of hydroxyl. The structures of the hydroxyl compounds were investigated with the FTIR spectrometer. The polyurethane was produced from the different vegetable oil-based polyols and commercial polyols. The characteristic properties of the polyurethane such as thermal conductivity, the structures of porosity, density were determined. The polyurethane produced from the different vegetable oils is being compared one another in terms of thermal properties.

The improvement in the thermal properties of polyurethane is quite important in terms of energy efficiency since polyurethane is used for insulation in the building. Therefore, the thermal properties of the polyurethane produced from the vegetable oils have tried to improve by using different type of catalyst. Polyurethane catalysts help to improve the mechanical and thermal properties and are asked to contribute to the economy by reducing dependence on foreign raw materials towards polyol synthesized from vegetable oil. It also created to compare the actual results with theoretical models and the damage to the environment of raw materials used in production are intended to minimize.

In this study the viscosities of the polyols produced from different the vegetable oils were measured by using a rotary viscometer (Brookfield DV-II) at different temperatures $\left(25,30,35,40,45\right.$ and $\left.50{ }^{\circ} \mathrm{C}\right)$. Samples were sheared with several different rotational speeds $(2.5,5,10,20,30$ and $50 \mathrm{rpm})$ at an increasing order. Data obtained for apparent viscosity and rotational speed were used to describe the flow behavior by the model equations.

\section{Mathematical Models}

Brookfield rotational viscometer (Model DV-II, Brookfield Engineering Laboratories) equipped with spindle 21 was used. Enough samples nearly $8 \mathrm{~mL}$ in the beaker were used to immerse the groove on the spindle with guard leg. Temperature was kept constant using thermostatically controlled electrical system. Shear rate $(\gamma)$ and shear stress $(\tau)$ were read from viscometer directly. Shear stress and shear rate can also be calculated by using Eq. (1), (2) and (3).

$\gamma=\beta . N$

$\tau=\mu . \gamma$

$\tau=\mathrm{k} .(\gamma)^{\mathrm{n}}$

Where; $\mathrm{N}$ is rotational speed (rpm), $\tau$ is shear stress $(\mathrm{Pa}), \mu$ is the apparent viscosity ( $\mathrm{mPa} . \mathrm{s}), \mathrm{k}$ is the consistency coefficient (mPa.s), $\mathrm{n}$ is flow behavior index and $\beta$ is coefficient (dimensionless).

$\mu_{\text {linear }}=\mathrm{A} . \mathrm{T}+\mathrm{B}$

$\mu_{\text {exponential }}=\mathrm{C} \cdot \exp (\mathrm{D} \cdot \mathrm{T})$

$\mu_{\text {power }}=\mathrm{E} \cdot \mathrm{T}^{\mathrm{F}}$

$\mu_{\text {logarithmic }}=\mathrm{G} \cdot \ln (\mathrm{T})+\mathrm{H}$

$\mu_{\text {polynomial }}=\mathrm{I} \cdot \mathrm{T}^{2}+\mathrm{J} . \mathrm{T}+\mathrm{K}$

$\mu_{\text {new }}=\exp (-\mathrm{T})+\mathrm{a} \cdot \mathrm{T}+\mathrm{b}$

\section{Figures and Tables}

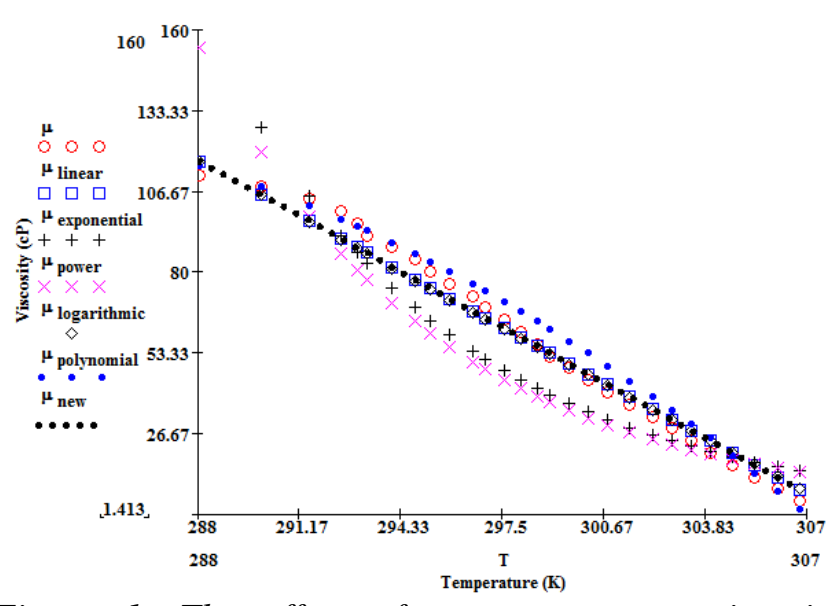

Figure 1. The effect of temperature on viscosity, hazelnut oil-based polyols $(H)$, comparison with model equations. 


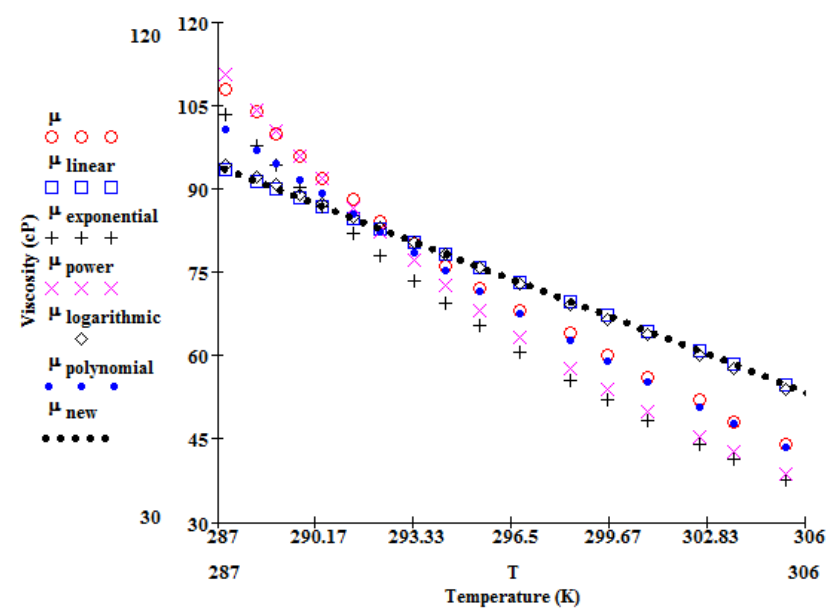

Figure 2. The effect of temperature on viscosity, canola oil-based polyols $(\mathrm{Ca})$, comparison with model equations.

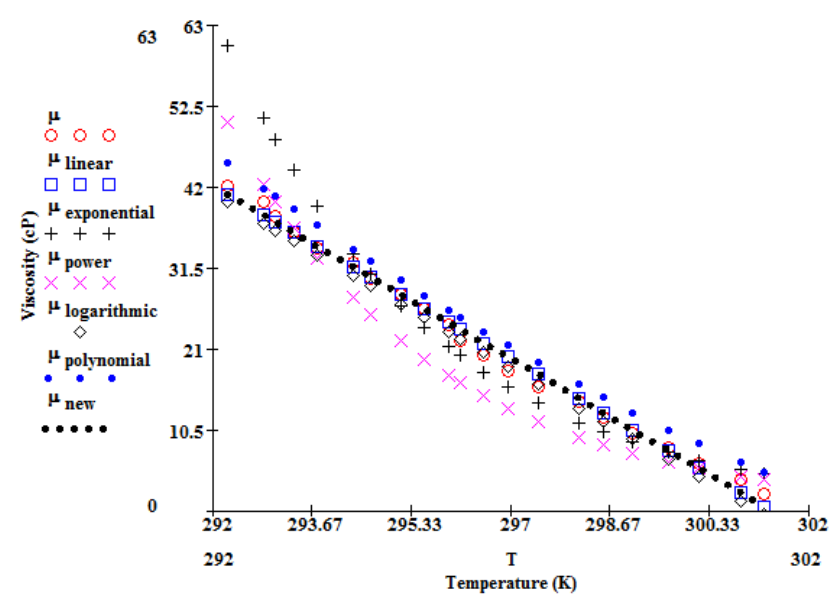

Figure 3. The effect of temperature on viscosity, linseed oil-based polyols (L), comparison with model equations.

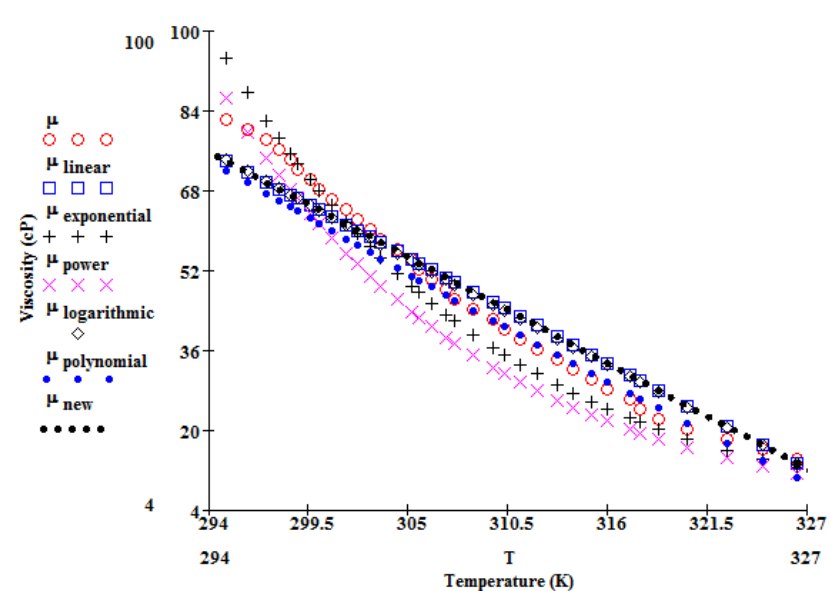

Figure 4. The effect of temperature on viscosity, corn oil-based polyols (Co), comparison with model equations.

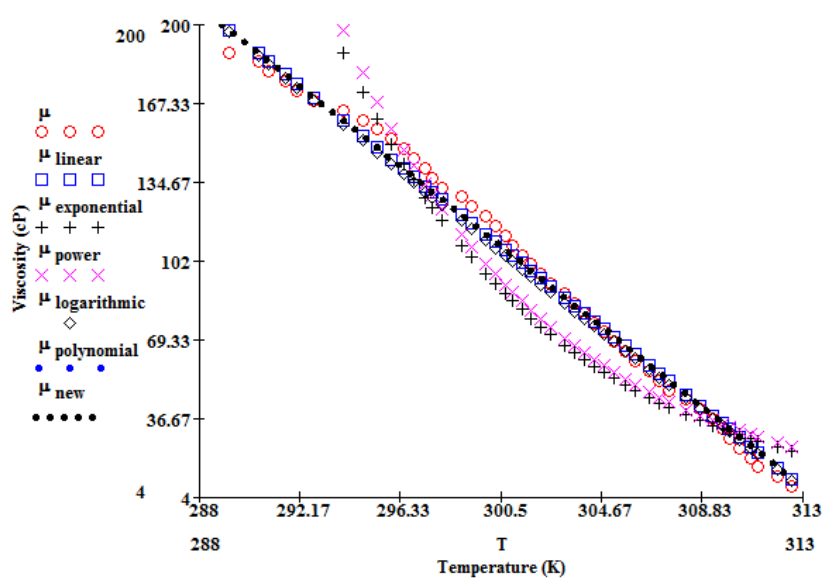

Figure 5. The effect of temperature on viscosity, cottonseed oil-based polyols (Cs), comparison with model equations.

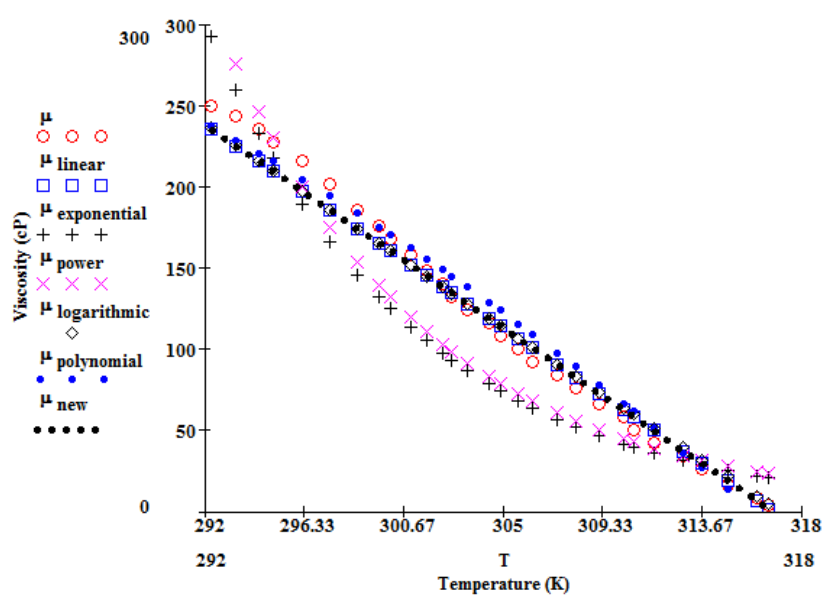

Figure 6. The effect of temperature on viscosity, soybean oil-based polyols $(S)$, comparison with model equations.

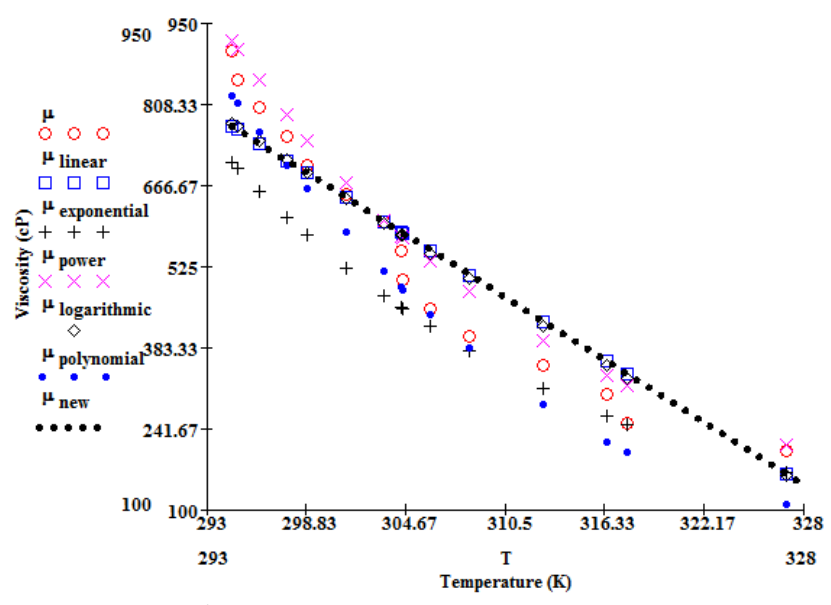

Figure 7. The effect of temperature on viscosity, commercial polyols $(C)$, comparison with model equations. 


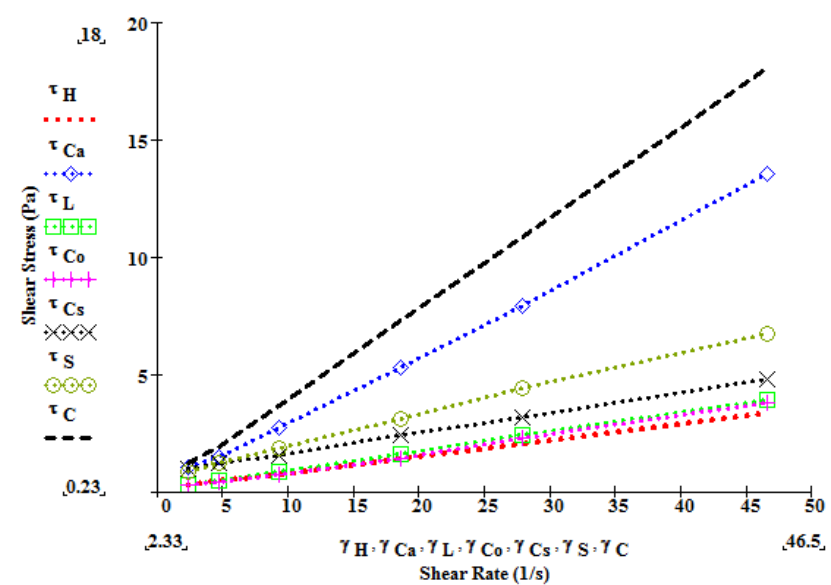

Figure 8. Shear stress vs shear rate for different vegetable oil-based polyols

Table 1. Correlation coefficients for linear model

\begin{tabular}{|l|c|c|c|}
\hline Polyols & $\mathrm{A}$ & $\mathrm{B}$ & $\mathrm{R}^{2}$ \\
\hline Soybean & -9.6579 & 3058.5 & 0.9702 \\
\hline Cotton & -7.9912 & 2508.7 & 0.9855 \\
\hline Corn & -1.9308 & 643.23 & 0.9588 \\
\hline Hazelnut & -5.8209 & 1793.2 & 0.9567 \\
\hline Canola & -2.1367 & 707.18 & 0.9296 \\
\hline Linseed & -4.4974 & 1355.3 & 0.9929 \\
\hline
\end{tabular}

Table 2. Correlation coefficients for exponential model

\begin{tabular}{|l|l|l|l|}
\hline Polyols & \multicolumn{1}{c|}{$\mathrm{C}$} & $\mathrm{D}$ & $\mathrm{R}^{2}$ \\
\hline Soybean & $2.10^{6}$ & -0.109 & 0.7668 \\
\hline Cotton & $5.10^{16}$ & -0.113 & 0.7897 \\
\hline Corn & $2.10^{10}$ & -0.065 & 0.8920 \\
\hline Hazelnut & $4.10^{18}$ & -0.131 & 0.7809 \\
\hline Canola & $1.10^{9}$ & -0.056 & 0.9653 \\
\hline Linseed & $5.10^{37}$ & -0.283 & 0.9066 \\
\hline
\end{tabular}

Table 3. Correlation coefficients for power law model

\begin{tabular}{|l|l|l|l|}
\hline Polyols & \multicolumn{1}{|c|}{$\mathrm{E}$} & $\mathrm{F}$ & $\mathrm{R}^{2}$ \\
\hline Soybean & $6.10^{82}$ & -32.56 & 0.7542 \\
\hline Cotton & $7.10^{85}$ & -33.85 & 0.7809 \\
\hline Corn & $4.10^{51}$ & -20.11 & 0.8773 \\
\hline Hazelnut & $1.10^{97}$ & -38.55 & 0.7717 \\
\hline Canola & $2.10^{44}$ & -17.19 & 0.9593 \\
\hline Linseed & $4.10^{208}$ & -83.91 & 0.9044 \\
\hline
\end{tabular}

Table 4. Correlation coefficients for logarithmic model

\begin{tabular}{|l|l|l|l|}
\hline Polyols & \multicolumn{1}{c}{$\mathrm{G}$} & $\mathrm{H}$ & $\mathrm{R}^{2}$ \\
\hline Soybean & -2906 & 16736 & 0.9667 \\
\hline Cotton & -2400 & 13798 & 0.9830 \\
\hline Corn & -601.1 & 3492.4 & 0.9600 \\
\hline Hazelnut & -1721 & 9862.8 & 0.9524 \\
\hline Canola & -663.2 & 3848.3 & 0.9404 \\
\hline Linseed & -1335 & 7619.5 & 0.9935 \\
\hline
\end{tabular}

Table 5. Correlation coefficients for polynomial model

\begin{tabular}{|c|c|c|c|c|}
\hline Polyols & $\mathrm{I}$ & $\mathrm{J}$ & $\mathrm{K}$ & $\mathrm{R}^{2}$ \\
\hline Soybean & -0.095 & 47.629 & -5576.5 & 0.979 \\
\hline Cotton & -0.105 & 55.433 & 7025.3 & 0.995 \\
\hline Corn & 0.006 & -5.377 & 1179.4 & 0.961 \\
\hline Hazelnut & -0.144 & 79.46 & -10842 & 0.987 \\
\hline Canola & 0.039 & -26.51 & 4465.6 & 0.994 \\
\hline Linseed & 0.132 & -82.93 & 12991 & 0.998 \\
\hline
\end{tabular}

Table 6. Correlation coefficients for new model

\begin{tabular}{|c|c|c|c|}
\hline Polyols & $\mathrm{a}$ & $\mathrm{b}$ & $\mathrm{R}^{2}$ \\
\hline Soybean & -9.65795 & 3058.480 & 0.9996 \\
\hline Cotton & -7.97888 & 2505.030 & 0.9997 \\
\hline Corn & -1.93083 & 643.2298 & 0.9998 \\
\hline Hazelnut & -5.82090 & 1793.152 & 0.9998 \\
\hline Canola & -2.13662 & 707.1342 & 0.9997 \\
\hline Linseed & -4.49741 & 1355.300 & 1.0000 \\
\hline
\end{tabular}

\section{Results and Discussion}

In this study, the temperature dependence of the viscosity of the vegetable oil-based polyol; model equations compared with experimental data. In Figures: 1, 2, 3, 4, 5, 6 and 7; the variation of apparent viscosities of polyols as a function of temperature were compared with model equations and experimental results. Operating temperatures of the assay were measured by raising temperature stepwise in a water bath. Waste vegetable oil-based polyols were measured by different rotational speeds $(2.5,5,10,20,30$ and $50 \mathrm{rpm})$ at an increasing order. According to the experimental results regression coefficients of model equations (4), (5), (6), (7), (8) and (9) were determined.

In this study, variations of viscosities of soybean oil, cottonseed oil, corn oil, hazelnut oil, canola oil, linseed oil-based polyols and commercial polyols were determined a function of temperature. It is known that the viscosity of the fluid decreases as temperature increases. The tested polyols showed Newtonian and non- Newtonian fluids behavior at certain temperature range.

As can be seen in Figures (1), (2), (3), (4), (5), (6) and (7) the viscosities of all types polyols irrespective of their production sources decrease substantially with increasing temperature. Heating may rapture molecular entanglement and bonds may stabilize the molecular structure and reduce the effect molecular volume in the polyols. In other words, as temperature increases, thermal energy of 
molecules increases and molecular distance develop due to reduction of intermolecular force and hence viscosity of fluid decreases. When thermal energy of molecules increases, molecular entanglement aligns easily and molecular structure stabilizes quickly since the molecules with high thermal energy move over one another easily.

As can be seen in Figure 8 the highest viscosity belongs to the commercial polyols while the lowest viscosity belongs to the polyol obtained from the raw hazelnut oil. The viscosities of polyols from high to low can be put in order as $\mu_{\mathrm{c}}>\mu_{\mathrm{ca}}>\mu_{\mathrm{s}}>$ $\mu_{\mathrm{cs}}>\mu_{\mathrm{c}}>\mu_{\mathrm{L}}>\mu_{\mathrm{co}}>\mu_{\mathrm{h}}$, here $\mu_{\mathrm{c}}, \mu_{\mathrm{ca}}, \mu_{\mathrm{s}}, \mu_{\mathrm{cs}}, \mu_{\mathrm{c}}, \mu_{\mathrm{L}}$, $\mu_{\mathrm{c} 0}$ and $\mu_{\mathrm{h}}$ denote the viscosities of commercial polyol and polyols obtained from raw canola oil, soybean oil, cottonseed oil, linseed oil, corn (maize) oil and raw hazelnut oil, respectively. Furthermore it can been seen that all types of polyols show almost Newtonian behavior.

The regression coefficients and correlation coefficients of each model equation for each polyol obtained from different vegetable oils are given Tables 1, 2, 3, 4 and 5. As can be figured out from comparison of Tables, high values of R-squared were obtained for polynomial model irrespective of polyols obtained sources. Moreover, the developed new model has the highest values for R-squared.

Several types of polyurethane structures were produced with the waste vegetable oil based polyols. The effective thermal conductivities of these structures were measured. The influences of the thermal conductivity of polyurethane, the porosity, the size and spatial distribution of pores on the effective thermal conductivity of these structures were analyzed. The results indicated that the effective thermal conductivity of the polyurethane varied between $0.020 \mathrm{~W} / \mathrm{m} \mathrm{K}$ and $0.030 \mathrm{~W} / \mathrm{m} \mathrm{K}$. Effective thermal conductivity was measured with TLS 100 instrument according to method of ASTM D5334.

In addition, density of polyurethane samples produced from vegetable base-polyols were measured to be 18 and $55 \mathrm{~kg} / \mathrm{m}^{3}$. Density is inversely proportional with effective thermal conductivity.

The petroleum-based polyols and vegetable-based polyols have different hydroxyl numbers, which were used to produce polyurethane. Waste vegetable oil based polyol in different ratios were added into the petroleum-based polyols. The mechanical properties of the polyurethane produced in the present study decreased with increasing waste vegetable oil based polyol ratios. In the experimental study, the hydroxyl numbers of vegetable-based polyols were optimized by varying temperature, reaction time and catalyst.

Waste vegetable oil-based polyols increases the number of hydroxyl groups and thus polyurethane bonding becomes stronger.

The temperature dependent-apparent viscosity of vegetable oil-based polyol; model equations and experimental data were compared with one another.

The operating temperature of the assay was measured by raising temperature stepwise in a water bath. According to the experimental data; the linear and non-linear regression were made to determine coefficients of regression in the model equations.
Abbreviations
$\mathrm{H}$ : Hazelnut oil-based polyols
Ca: Canola oil-based polyols
L: Linseed oil-based polyols
Co: Corn oil-based polyols
Cs: Cottonseed oil-based polyols
S: Soybean oil-based polyols
C: Commercial polyols
$\mu$ : Apparent viscosity (cP)
$\gamma$ : Shear rate $(1 / \mathrm{s})$
$\tau$ : Shear stress
$\mathrm{N}$ : Rotational speed (rpm)
$\mathrm{k}$ : Consistency coefficient (mPa.s)
$\mathrm{n}$ : Flow behavior index
$\beta$ : Coefficient (dimensionless)

\section{References}

[1] A. Andersson, S. Lundmark, A. Magnusson and F. H. J. Maurer, "Vibration and Acoustic Damping of Flexible Polyurethane Foams Modified with a Hyper branched Polymer," Journal of Cellular Plastics, vol. 01, pp. 01-21, 2009.

[2] J. L. R. Armenta, T. Heinze and A. M. M. Martinez, "New Polyurethane Foams Modified with Cellulose Derivatives," European Polymer Journal, vol. 40, pp. 2803-2812, 2004.

[3] R. Bashirzadeh and A. Gharehbaghi, "An investigation on reactivity, mechanical and fire properties of PU flexible foam," Journal of Cellular Plastics, vol. 01, pp. 01-30, 2009.

[4] X. C. Bian, J. H. Tang and Z. M. Li, "Flame retardancy of whisker silicon oxide/rigid polyurethane 
foam composites with expandable graphite," Journal of Applied Polymer Science, vol. 110, pp. 3871-3879, 2008.

[5] X. C. Bian, J. H. Tang and Z. M. Li, "Flame retardancy of hollow glass microsphere/rigid polyurethane foams in the presence of expandable graphite," Journal of Applied Polymer Science, vol. 110, pp. 3871-3879, 2008.

[6] D. S. Han, I. B. Park, M. H. Kimi, B. J. Noh, W. S. Kim and J. M. Lee, "The effects of glass fiber reinforcement on the mechanical behavior of polyurethane foam," Journal of Mechanical Science and Technology, vol. 24, pp. 263-266, 2010.

[7] L. Indennidate, D. Cannoletta, F. Lionetto, A. Greco and A. Maffezzoli, "Nanofilled polyols for viscoelastic polyurethane foams," Society of Chemical Industry, vol. 59, pp. 486-491, 2009.

[8] A. A. Lubguban, Y. C. Tu, Z. R. Lozada, F. H. Hsieh and G. J. Suppes, 2009, "Noncatalytic polymerization of ethylene glycol and epoxy molecules for rigid polyurethane foam applications," Journal of Applied Polymer Science, vol. 112, pp. 2185-2194, 2009.

[9] X. Y. Meng, L. Ye, X. G. Zhang, P. M. Tang, J. H. Tang, X. Ji, and Z. M. Li, "Effects of expandable graphite and ammonium polyphosphate on the flameretardant and mechanical properties of rigid polyurethane foams," Journal of Applied Polymer Science, vol. 114, pp. 853-863, 2009.

[10] D. Mello, S. H. Pezzin and S. C. Amico, "The effect of post-consumer pet particles on the performance of flexible polyurethane foams", Polymer Testing, vol. 28, pp. 702-708, 2009.

[11] F. S. Michel, L. Chazeau and J. Y. Cavaillé, "Mechanical properties of high density polyurethane foams: II effect of the filler size," Composites Science and Technology, vol. 66, pp. 2709-2718, 2006.

[12] M. A. Mosiewicki, G. A. Dell'Arciprete, M. I. Aranguren and N. E. Marcovich, "Polyurethane foams obtained from castor oil-based polyol and filled with wood flour," Journal of Composite Materials, vol. 01, pp. 1-16, 2009.

[13] M. M. A. Nikje and Z. M. Tehrani, "Thermal and mechanical properties of polyurethane rigid foam/modified nanosilica composite," Polymer Engineering and Science, vol. 50, pp. 468-473, 2010.

[14] M. M. A. Nikje and Z. M. Tehrani, "Polyurethane rigid foams reinforced by doubly modified nanosilica," Journal of Cellular Plastics, vol. 01, pp. 01-14, 2010.

[15] I. Racz, E. Andersen, M. I. Aranguren and N. E. Marcovich, "Wood flour-recycled polyol based polyurethane lightweight composites," Journal of Composite Materials, vol. 43, pp. 2871-2884, 2009.
[16] J. P. Sadowska and B. Czupryński, "New compounds for production of polyurethane foams," Journal of Applied Polymer Science, vol. 102, pp. 5918-5926, 2006.

[17] M. Thirumal, K. Dipak, N. K. Singha, B. S. Manjunath and Y. P. Naik, "Effect of a nanoclay on the mechanical, thermal and flame retardant properties of rigid polyurethane foam," Journal of Macromolecular Science, vol. 46, pp. 704-712, 2009.

[18] M. Thirumal, N. K. Singha, K. Dipak, B. S. Manjunath and Y.P. Naik, "Halogen-free flameretardant rigid polyurethane foams: effect of alumina trihydrate and triphenylphosphate on the properties of polyurethane foams," Journal of Applied Polymer Science, vol. 116, pp. 2260-2268, 2010. 